\title{
Analysis of the Relationship between CCP and Politics and Law in Criminal Litigation of Zhen Peng's Democratic and Legal Thought
}

\author{
Pengfei $\mathrm{Li}^{1}{ }^{1, \mathrm{a},{ }^{*}}$ \\ ${ }^{1}$ Law School, Shanxi University of Finance and Economics, Taiyuan030006, China.
}

a751559067@qq.com

\begin{abstract}
Comrade Zhen Peng is one of the main founders of the socialist legal system in China. $\mathrm{He}$ has created an indelible historical merit for the socialist revolution and construction, and especially for the construction of socialist democracy and legal system, and the liberation of the Chinese people as well as the establishment of the new China. Among which, the thought on the relationship between CCP and law by Zhen Peng has a great referenced significance for the construction of our clean government and socialist democratic legal system after the eighteenth National Congress of the CPC. CCP has a status of directing the overall situation and coordinating all parties in the overall situation of the country, therefore they should shoulder the responsibility of leading legislation and law-keeping naturally. The prominence of this status relies on the realization of the role of CCP. But the role of CCP is realized by the establishment of party groups within the political and legal departments and the grading management of the party's political and legal levels, that is, the establishment of political and legal work departments. Moreover, the role of the CCP is mainly played by grading management of political and legal levels, so the prominence of the position of the Commission of Politics and Law (the CPL) in CCP is of decisive significance. Consequently, how to standardize the relationship between CCP and law and realize the benign development of these two factors as well as the independent adjudication in criminal litigation need us do more in the reform of leadership and judicial system.
\end{abstract}

Keywords: Grading management; commission of politics and law; principle of the people's courts and people's procuratorates exercise their powers independently according to law; independent adjudication.

\section{Introduction}

Zhen Peng had served as one of the leaders of CCP and our country for a long time, and had long struggled in the front line of political and legal work. Many of his ideas have provided solid theoretical support for the construction of socialist democracy and the rule of law in China. In order to solve and cope with the new problems and new situations that have emerged in the construction of socialist democracy and the rule of law in China in the early stage of reform and opening up, Comrade Zhen Peng once pointed out that: To consolidate the party's ruling status and strengthen political power construction, it is necessary to handle the relationship between the party and the state, the relationship between the people's congress and the government, and the personal and collective relations between the people's congress and its standing committee. In order to correctly handle the relationship between the three, Zhen Peng did in-depth research and serious thinking. Comrade Zhen Peng continued to point out: In our country, the party leads the people to formulate the Constitution and laws, and the party also leads the people to abide by and enforce the Constitution and laws. The party itself must also operate within the scope of the Constitution and laws. It is unanimous and unified to uphold the leadership of the party, to comply with the people's mastery of the country, and to act in strict accordance with the law. This view scientifically answers the relationship between the party and the people and the state power. It has become the ideological root of the fundamental principle of building a socialist democracy and legal system, which is put forward by the 16th Party Congress, "Strengthening the Party's leadership, the people being the masters of the country, and the rule of law." However, in the practice of criminal proceedings, especially before the 18th National Congress of the CCP, the situation of political parties intervening in the judicial, supervising cases and inducing false and wrongful cases does exist. Therefore, how to grasp the "degree" of the relationship between 
the party and politics and law, and truly implement and implement the principle of "holding on the leadership of the party, (conforming) the people as the masters of the country, and (strictly) doing things according to law (governing the country)" The benign development of relations with politics and law has become one of the most urgent problems to be solved.

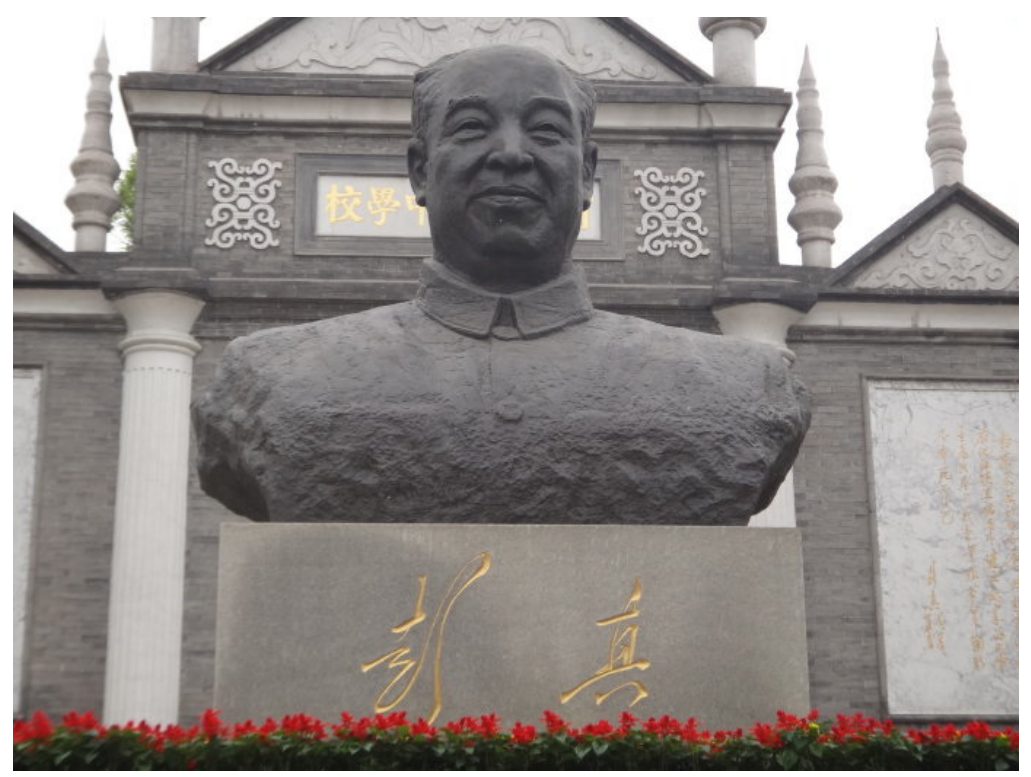

Fig 1. Zhen Peng's statue in Wenying Park, Taiyuan, China.

\section{The Leadership of CCP and the Grading Management in the Field of Politics and Law}

\subsection{The Realization Form of CCP's Role in the Field of Politics and Law}

To realize the benign development of the relationship between the party and politics and law, we must first make it clear that: The realization of CCP's status and role in the field of politics and law. The so-called political and legal means that "the law that reflects the will of the state must serve the political". Therefore, answering the way to realize the status and role of the party in the field of politics and law is to answer how the party reflects the core position of leadership in the field of politics and law and how to realize the law as a political service. In the field of politics and law, the role of CCP is played through the grading management of political and legal, that is, to establish party groups or political and legal work departments within the public security organs, procuratorial organs and courts at all levels. In which, the most important way is to establish a political and legal work department--- the CPL.

\subsection{The Basic Content of the CPL System}

The CPL is the functional department of the party committee and is the management of political and legal work whose main tasks are to guide, coordinate and supervise people's procuratorates, courts, public security organs, judicial administration, and national security departments to carry out their work and maintain social stability.

\subsection{Relationship between the PLC and Party Committees at the Same Level}

Comrade Zhen Peng elaborated on the work to be done by the CPL at the first meeting of the Central CPL in 1980, which is to propose work plans, to do organizational work and to be a staff. It can be seen that the CPL should be positioned as an assistant and staff officer of the party's leadership in political and legal work. This is the relationship between the CPL and the party committee at the same level.

It should be noted that the field of criminal litigation is a test field for the benign development of the relationship between the party and politics and law. Then, after clarifying the way in which the 
party's role in the field of politics and law is realized and the relationship between the CPL and the party committee at the same level, it is advisable to further study the relationship between the CPL and the specific political and legal departments from the field of criminal proceedings. Only by it, can we find problems and solve problems.

\section{The Relationship between the CPL and Public Security Organs, Procuratorial Organs and Courts in the Field of Criminal Litigation}

\subsection{The Internal Relationship between These Three Organs}

\subsubsection{Division of Labor}

First of all, these three organs are responsible for the division of labor and perform their own duties, which is that the public security Organs are responsible for investigation, procuratorial organs for review and prosecute and court for trial. When dealing with a criminal case, these three divisions are responsible for each other's duties, and each of them performs their duties within the set scope of their own functions and powers to ensure the internal independence of criminal litigation.

\subsubsection{Cooperate}

Secondly, these three organs are also mutually cooperative relations. As before, in a general criminal case, public security organs are required to conduct administrative detention and investigation first. And the expiration of the detention period is subject to the approval of the procuratorial organ for arrest; after the investigation is completed, it is submitted to the procuratorial organ for review and prosecution. After the procuratorate initiates a public prosecution, the people's court accepts the case, independently makes the referee and submits it to the public security organ for execution. In this way, the validity of criminal litigation is guaranteed.

\subsubsection{Mutual Restraint}

Finally, these three organs are mutually restrained. If the people's procuratorate believes that the suspect is not in compliance with the conditions of arrest, the public security organ shall immediately release the suspect or change the compulsory measures. When reviewing the prosecution, if the evidence is insufficient, it may be returned to the public security organ for supplementary investigation. The public security organ may also apply to the higher-level procuratorial organ for reconsideration in response to the relevant decision; after the people's procuratorate has filed a public prosecution, the people's court may consider that the criminal facts are unclear and the evidence is insufficient. If the prosecution is dismissed, the people's procuratorate may file a protest, and the people's court may dismiss the protest; the people's procuratorate may also conduct trial supervision over the effective judgment and supervise the investigation, trial, and execution. In this way, the fairness of the public prosecution law case is reflected.

\subsection{The External Relationship between the CPL and These Three Organs}

\subsubsection{The CPL Directs the Work of These Three Organs}

The CPL's direction reflects in these two aspects: Leadership within the party and other macro guidance which has no substantive work content. Therefore, in such relationship, these three organs should accept the guidance of the CPL consciously.

\subsubsection{The CPL Coordinates the Work of These Three Organs}

The coordination role of CPL is mainly reflected in it coordinating social governance and maintaining social order, which is to coordinate every one of politics and law department to restrict each other but make them closely coordinated at the same time, thus helps organizing and coordinating the comprehensive management of social security and promote the implementation of various measures. Therefore, these three organs should actively cooperate with the work of the CPL. 


\subsubsection{The CPL Supervises the Work of These Three Organs}

The supervision role of the CPL on these three organs is mainly reflected in the implementation of law enforcement supervision by the CPL. It vigorously supports and strictly supervises these three organs to exercise their functions and powers, and conducts law enforcement supervision over the obvious violations of these three organs. Therefore, under this relationship, these three organs should accept the supervision of the CPL consciously.

\section{System Disadvantages of This Relationship Currently}

Through the evaluation of independent trial standards, combined with the above-mentioned three organs system and the relative relationship between those three organs and the CPL, it is not difficult to find many shortcomings under the CPL system.

\subsection{The Existing Problems and Drawbacks}

First of all, the CPL system lacks a statutory basis. And it is founded by the policy of CCP .However, since CCP leads the state power, of course, it leads the state's judiciary, which makes sense from the legal point of view. Since the CPL is enough to influence the judiciary, it is necessary to formulate a statute law to regulate it, but not to negate the necessity of legislation in the guise of party and government separation.

Secondly, there have many defects on the implementation of CPL system, which mainly reflects in these three aspects: lack of rationality in the leadership system, lack of certainty in the authority range and lack of stability in the authority of CPL.

Above all, the system of CPL weakens the relationship of independence and checks and balances between the public security organs, procuratorate organs and court, which is of significance for judicial justices. And once the relationship of independence and checks and balances between these three organs are weakened and the procedural justice is undermined, it is difficult to avoid the occurrence of false and wrongful cases, the case of Xianglin She and Zuohai Zhao for instance.

\subsection{Roots of the Existing Drawbacks}

Roots of the existing drawbacks of the current CPL system is mainly lying in four aspects: the tradition of marginalization of judicial status, the party's policy and legal system need to be further balanced, defects of party building and the politics respect less for administration of justice. And each of which need us to do more to improve the situation of the current CPL system.

\section{Conclusion}

However, it must be made clear that although the CPL system has many shortcomings, its establishment is in line with China's national conditions and practices and has positive significance, which is embodied in the following points: (1) The establishment of the CPL system guarantees a unified judicial system for our country. (2) The establishment of the CPL system ensures the core position of CCP in the judicial field and is conducive to the promotion and implementation of the party policy. (3) The CPL system is in line with the national nature of the people's democratic dictatorship and the principle of organizational activities of democratic centralism (4)The CPL system is conducive to discovering and studying practical issues and maintaining social order. But we cannot evade the existing defects of the CPL system. Instead, we should take a more active stance to overcome difficulties, change the status quo, and realize the benign development of the relationship between the party and politics and law. Consequently, we should face the problem positively and to do more in party building, strengthening supervision and grasping the basic principles of the relationship between the party and politics. Maybe by these, can we achieve the organic unity of democratic concentration and independent judiciary, the unity of the fairness and efficiency value of criminal litigation and the goal of building a country ruled by law. 


\section{References}

[1]. Bing Han. The Three Relationships of Zhen Peng 's Deep Thoughts [J]. China Organization Personnel News, 2014.

[2]. Men Hour. The Formation and Significance of Contemporary Chinese Political and Legal System [J]. Chinese Journal of Law, 2016.

[3]. Lieu Zhu. Zhen Peng and the Construction of Socialist Democracy and Rule of Law in China [M], Renmin University of China Press, 2014.

[4]. Xiaoping Deng. Selected Works of Xiaoping Deng [M]. People's Publishing House, 1993. 